Research

\title{
Infant temperament contributes to early infant growth: A prospective cohort of African American infants Meghan M Slining*1, Linda Adair ${ }^{1,2}$, Barbara Davis Goldman³, Judith Borja² and Margaret Bentley ${ }^{1,2}$
}

Address: ${ }^{1}$ Department of Nutrition, School of Public Health, University of North Carolina at Chapel Hill, Chapel Hill, NC, USA, ${ }^{2}$ Carolina Population Center, University of North Carolina at Chapel Hill, Chapel Hill, NC, USA and ${ }^{3}$ Frank Porter Graham Child Development Institute, University of North Carolina at Chapel Hill, Chapel Hill, NC, USA

Email: Meghan M Slining* - slining@email.unc.edu; Linda Adair - linda_adair@unc.edu; Barbara Davis Goldman - goldman@mail.fpg.unc.edu; Judith Borja - judithborja@gmail.com; Margaret Bentley - mbentley@unc.edu

* Corresponding author

Published: 5 August 2009

International Journal of Behavioral Nutrition and Physical Activity 2009, 6:5I

This article is available from: http://www.ijbnpa.org/content/6/1/5I

(c) 2009 Slining et al; licensee BioMed Central Ltd.

This is an Open Access article distributed under the terms of the Creative Commons Attribution License (http://creativecommons.org/licenses/by/2.0), which permits unrestricted use, distribution, and reproduction in any medium, provided the original work is properly cited.

\begin{abstract}
Background: Prospective studies linking infant temperament, or behavioral style, to infant body composition are lacking. In this longitudinal study (3 to 18 months), we seek to examine the associations between two dimensions of infant temperament (distress to limitations and activity level) and two anthropometric indicators (weight-for-length z-scores (WLZ) and skin fold (SF) measures) in a population at high risk of overweight.

Methods: Data are from the Infant Care and Risk of Obesity Project, a longitudinal study of North Carolina low income African American mother-infant dyads $(n=206)$. Two temperament dimensions were assessed using the Infant Behavior Questionnaire-Revised. A high distress to limitations score denotes an infant whose mother perceives that $\mathrm{s} / \mathrm{he}$ often cries or fusses, and a high activity level score one who moves his/her limbs and squirms frequently. Cross-sectional analyses were conducted using ordinary least squares regression. Fixed effects longitudinal models were used to estimate anthropometric outcomes as a function of time varying infant temperament.

Results: In longitudinal models, increased activity levels were associated with later decreased fatness and WLZ. In contrast, high levels of distress to limitations were associated with later increased fatness at all time points and later increased WLZ at 12 months.

Conclusion: Infant temperament dimensions contribute to our understanding of the role of behavior in the development of the risk of overweight in the formative months of life. Identification of modifiable risk factors early in life may help target strategies for establishing healthy lifestyles prior to the onset of overweight.
\end{abstract}

\section{Background}

Overweight and obesity have increased rapidly in the U.S., especially among African American children. [1,2] Prevention of overweight needs to begin early in life, as child- hood overweight often tracks into adulthood $[3,4]$ and is associated with the development of adverse health outcomes both during childhood [5,6] and during later adulthood. [7] Weight gain and body size, even during the 
early months of life, influence weight status later in childhood, as well as the development of adult cardiovascular and metabolic disease. [8-11]

The determinants of infant somatic growth are not well understood. While parental behavioral and demographic characteristics are often considered salient influences on infant growth patterns (e.g. type and style of infant feeding and socioeconomic resources) [12-15], results are inconsistent. For example, low socioeconomic resources have been shown to contribute either to infant undernutrition $[16,17]$ or to overweight $[2,18]$. Furthermore less is known about the contribution of infant characteristics to parental feeding and care behaviors that may affect infant physical growth.

Conceptually there are at least three pathways (mechanisms) by which aspects of infant behavior could influence growth: (a) an infant's difficult or distressed behavior may contribute to the initiation of caretaking activities such as feeding that increase energy intake [19]; (b) an infant's difficult or distressed behavior may be expressed through crying and fussing which expend energy [20]; or (c) the amount and vigor of an infant's motor activity behavior may increase energy expenditure. Given that infant-initiated behavior may affect both sides of the energy balance equation, the role of infant behavioral style, or temperament, merits investigation.

Infant temperament refers to biologically rooted differences in behavior believed to be present early in life and relatively stable across time and context. [21] Temperament is composed of a number of traits or dimensions including fear, positive and negative affect, sadness, distress to limitations (crying and fussing) and activity level. Two of these temperament dimensions may be of particular importance for understanding variability in infant somatic growth through the pathways discussed above: distress to limitations (pathways a and $\mathrm{b}$ ) and activity level (pathway c).

Most evidence suggests that "difficult" temperament, a broader concept which includes considerable to excessive fussing and crying, or distress to limitations (DTL), is related to increased weight gain and body size as proposed in pathway (a) above. $[19,22,23]$ Two studies have related "difficult" temperament to increased weight gain in infancy. The first determined that difficult temperament, measured at 6 months of age, was slightly positively associated with rapid weight gain during the first 6 months of life [22] while the second showed that 12-month-old infants with the greatest weight gain had significantly more difficult temperament ratings at 6-months of age. [19] A third study found that DTL was related to fast gain in the first eight weeks of life. [23] While Wells et al. [20] did not find a relationship between DTL and infant fatness, their group found that higher DTL was associated with significantly higher levels of energy expenditure as proposed in pathway (b) above.

In contrast, the extant literature on the relationship between activity level and body size and composition is equivocal. Two studies showed an association between activity level and size, although in opposite directions. One found that heavy infants spent more time moving their arms and legs vigorously than did the light infants [24] while another found that leg activity was inversely associated with weight among female infants as proposed in pathway (c) above. [25] Conversely, two studies showed no association between activity level and size or body composition. One found that low activity levels at 6 months of age did not lead to higher body fatness at 12 months of age [26] while a second found that infants with the most decelerated growth from 6 to 12 months of age were not more active than those gaining the most. [19]

Previous studies on the relationship between temperament and body size have primarily focused on middleclass, white populations and have largely utilized crosssectional study designs. Longitudinal research is needed to improve our understanding of the early development of infant behavior patterns and how these patterns contribute to the development of infant size and body composition in infancy.

The objective of the current study was to examine the longitudinal associations from 3 to 18 months of 2 dimensions of infant temperament, DTL and activity level, with body size and fatness among low income African-American infants, a group at high risk for the development of obesity.

\section{Methods}

\section{Study Design and Participants}

We used data from the Infant Care, Feeding and Risk of Obesity Study (hereafter called Infant Care), a prospective cohort study that assessed mother/infant dyads from 3 to 18 months postpartum. The Infant Care study was primarily designed to examine, in the home environment, how parenting and infant feeding styles relate to infant diet, and the risk of infant overweight. First time African-American mothers aged 18-35 years and their 3-month-old infants were recruited through Women Infants and Children (WIC) clinics in North Carolina and were assessed during in-home visits when infants were approximately 3 , $6,9,12$, and 18 months of age. A total of 217 mothers and infants were recruited at baseline (3 months). Data collection was conducted from 2003-2007. For inclusion, mothers had to be willing to participate in home visits and assessments, and had healthy infants who had com- 
pleted $>35$ weeks' gestation. Infants with Down syndrome, epilepsy, cleft lip or palate, cerebral palsy, failure to thrive, mental retardation, severe food allergies or any condition that might affect appetite, feeding or growth were excluded from the study.

The analysis sample includes 206 infants (96 males, 110 females) with data on weight, length, dietary intake and temperament variables of interest. The protocol was approved by the School of Public Health Institutional Review Board at the University of North Carolina at Chapel Hill.

\section{Study Measurements and Variables}

Anthropometrics. Study personnel were trained in standard anthropometric techniques. Anthropometrics were measured at infant ages 3, 6, 9, 12 and 18 months. Weight was measured on a digital scale (Tanita BD-585 Digital Baby Scale) to the nearest $10 \mathrm{~g}$. Recumbent length was measured by a 2-person team, using a portable rigid length board (O'Leary Length Board) to the nearest 0.1 $\mathrm{cm}$. Infant skin fold thicknesses were measured using Harpenden calipers. All anthropometric measurements were done in triplicate and the mean was used in analyses. Weight-for-length z-scores (WLZ) were calculated using the CDC/NCHS 2000 growth reference [27]. Change in WLZ was calculated as a simple difference between subsequent WLZ measures. The main outcome variables of interest were WLZ and the sum of three skin fold (SF) measures (subscapular, abdominal and triceps). Birth weight and gestational age were obtained from maternal report.

Infant Temperament. Temperament refers to constitutionally-based individual differences in reactivity and self-regulation. [28] The continuity of temperamental characteristics over time and in different contexts is among the hallmarks of temperament theory. [29] Temperament was measured by maternal reports of the frequency of the occurrence of temperamentally relevant infant behaviors along a 7-point Likert-type scale across a number of temperamental dimensions.

At infant age 3, 6 and 9 months we examined 2 subscales of the Infant Behavior Questionnaire-Revised (IBQ-R) [30], distress to limitations (DTL) and activity level. The DTL subscale consists of 16 items, which characterize an infant's fussiness, crying and exhibition of distress in different situations. A high DTL score denotes an infant that often cries or fusses. Scores range from 1.6 to 5.8 in our sample (with a possible range of 1-7). The activity level subscale consists of 15 items, which capture movement of the infant's arms and legs, squirming and locomotor activity. A high activity score on the IBQ-R reflects an infant who squirms and moves his/her limbs often. Scores range from 1.9 to 6.3 in our sample (with a possible range of 1-7). The complete IBQ-R consists of 14 subscales. The validity of the IBQ-R scales has been reported elsewhere [31,32].

At infant age 12 and 18 months we used the toddler version of the IBQ-R, the Early Childhood Behavior Questionnaire (ECBQ). [33] The ECBQ does not include DTL. The activity level toddler subscale consists of 12 items, which capture level of gross motor activity, including rate and extent of locomotion. A high activity level score reflects a toddler who splashes when bathing, moves quickly from one place to another, seems full of energy, and is generally in motion rather than still. Scores range from 3.4 to 7.0 in our sample. The complete ECBQ consists of 18 subscales.

Given that the IBQ-R and ECBQ were developed using a predominantly Caucasian, middle class sample, [30] concern may be raised about the validity of this measure in our sample population. Four recent studies [34-37] used the IBQ-R with samples which included significant numbers of African-American families, single mothers, and low income families. While a confirmatory factor analysis has been conducted for US and Russian infants [38], to our knowledge a similar confirmatory factor analysis has not been conducted to examine whether the temperament subscales hold together in the same way for an African American sample. Cronbach's alpha coefficients were calculated for temperament subscales at each time point to assess internal consistency of the IBQ-R and ECBQ in our sample (range 0.69-0.78). All eight alphas calculated (2 subscales, each at 4 time points) exceeded 0.60 , the value considered the threshold for adequate internal consistency by DeVillis. [39]

Dietary intake. Three 24-hour dietary recalls were completed at each time point using the Nutrition Data System (version 2005 Nutrition Coordinating Center, University of Minnesota, Minneapolis). The first 24-hour recall at each time point $(3,6,9,12$ and 18 months) was completed during the home visit and was followed by two random nonconsecutive 24-hour recalls via telephone within a 2-week interval following the home visit. Food models and pictures were used during the assessment to aid in the estimation of portion sizes. Approximately 40 infant foods, including commercially prepared baby foods and cereals, were added to the digital food library of the Clinical Nutrition Research Unit at the University of North Carolina at Chapel Hill. Information on breast feeding was collected during in-home interviews. In all models, dietary intake was represented by the inclusion of three variables concurrently: a binary main effect breast feeding variable at the time of each visit (breast fed, not breast fed), a continuous main effect total energy intake variable 
representing energy intake from non-breast milk substances and a total energy intake by breast feeding interaction term. The latter is needed to account for the fact that energy intake was not measured for breast milk.

Covariates. We considered several covariates including: child sex, birth weight, and gestational age; maternal age, education, and BMI. We did not include income, since this information was not provided by more than half of the sample women. The current literature was the basis for selecting and evaluating these variables. [12,13,40-43]

\section{Statistical Analysis}

The analysis was conducted using STATA (version 10.0, College Station, TX) [44]. Descriptive statistics were calculated for anthropometrics, temperament measures and select sociodemographic factors. We used t- and chisquare statistics to test for differences between males and females for anthropometrics and temperament characteristics. Preliminary analyses suggested a non-linear relationship between the DTL temperament subscale and anthropometry. At each time point, we examined the shape of the relationships using locally weighted regression, or loess smoothing graphs [45]. Categorical variables (low, medium and high temperament subscale scores) were then created based on cut points where the slope of the relationship between DTL and anthropometry changed. Pearson correlations were computed to examine continuity of temperament measures between time points for each subscale separately. Effect measure modification by sex was examined by testing interaction terms using likelihood ratio tests, with $\alpha=0.15$. Mediation by infant diet was examined by comparing crude and diet adjusted cross-sectional models. Evidence for mediation was provided if the unique contribution of infant temperament to the anthropometric outcome was reduced and accounted for by diet, the presumed mediating variable [46]. Tests for confounding were conducted using an a priori change in estimate criterion (change in main effect coefficient of $>10 \%$ ).

Cross-sectional analyses were conducted at each time point using ordinary least squares regression models. Ordinary least squares longitudinal regression models with fixed effects methods were used to estimate anthropometric outcomes as a function of time varying diet and lagged infant temperament [47]. Lagged infant temperament variables were used so that inferences about potentially causal sequences could be drawn (i.e. to study how temperament predicts subsequent SF or WLZ). Preliminary cross-sectional analyses indicated that effects were not consistent over time and therefore effect measure modification by visit was examined by testing interaction terms using likelihood ratio tests, with $\alpha=0.15$. All models controlled for infant birthweight, gestational age, total energy intake, breastfeeding status and the interaction of breastfeeding with energy intake. To facilitate interpretation of results, WLZ values were predicted for low, medium and high temperament scores at each time point, holding all other variables at their means.

\section{Results}

Table 1 presents characteristics of the mothers and infants in our sample. At all time points, mean WLZ scores were positive, indicating that on average relative weight was higher than the $50^{\text {th }}$ percentile of the CDC/NCHS 2000 growth reference, with approximately $70 \%$ of the sample having positive WLZ at every time point. Mean WLZ and the mean sum of skinfolds (SF) decreased slightly from 318 months of age. In contrast, means of the mother's scores reflecting her perception of the infant's DTL and activity level increased slightly from 3-9 and 3-18 months of age, respectively. There were no statistically significant sex differences in any of the anthropometric or temperament measures. Compared to previous studies on temperament and weight status, $[20,22,23]$ the mothers in our sample had higher BMI, fewer years of education and lower rates of breastfeeding (Table 1).

Temperament subscales were moderately stable over time. Pearson correlations between the individual subscales of infant temperament measured at multiple time points during infancy ranged from 0.25 to 0.60 and were all significant at $p<.01$.

The results of the cross-sectional analyses are presented in Tables 2 and 3. There was no strong evidence that diet mediates the relationship between temperament and WLZ or SF; the temperament coefficients were not attenuated by inclusion of dietary variables. As diet was not found to be a mediator it was included as a covariate in all models. Activity level was a significant predictor of SF at 3 months only (Table 2 ). Infants whose mothers perceived them to be more active had lower SF $(\beta=-0.93, \mathrm{p}=0.02)$. Activity level was not a significant predictor of WLZ when measured concurrently at any time point. Preliminary analysis of the crude relationship between DTL and anthropometry suggested that it was nonlinear. DTL was not a significant predictor of either WLZ or SF (Table 3) at any point in the cross-sectional analyses.

The results of the fixed effects longitudinal analyses are presented in Tables 4 and 5. The relationship between lagged temperament and WLZ was found to change over time as indicated by the significant visit $\times$ temperament interaction terms. There was no evidence of a significant interaction between lagged temperament and visit in SF models, indicating that the associations did not differ by age of the child. Activity level was a significant predictor of subsequent fatness and relative weight (Table 4). Higher 
Table I: Descriptive characteristics of mothers and infants from 3-18 months of infant age

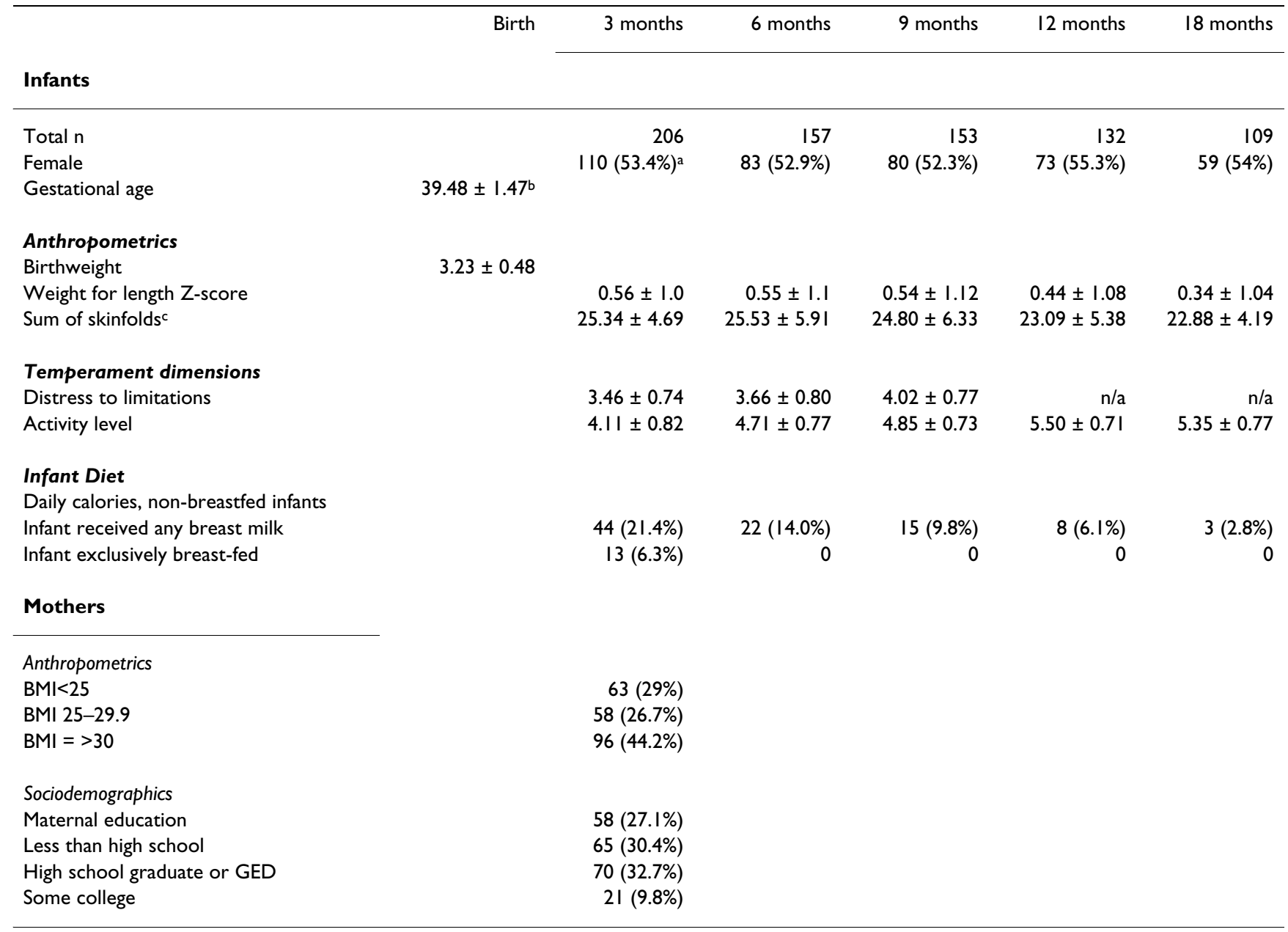

a Frequency $(\%)$

bMean \pm standard deviation

c Sum of 3 skinfolds: subscapular, abdominal and tricep

Table 2: Cross-sectional Results: Activity Temperament Dimension and Infant Anthropometry

\begin{tabular}{|c|c|c|c|c|c|c|c|c|c|c|}
\hline & \multicolumn{2}{|r|}{3 month visit } & \multicolumn{2}{|r|}{6 month visit } & \multicolumn{2}{|r|}{9 month visit } & \multicolumn{2}{|c|}{12 month visit } & \multicolumn{2}{|c|}{18 month visit } \\
\hline & $n$ & $\beta(95 \% \mathrm{Cl})^{\mathrm{a}}$ & $n$ & $\beta(95 \% \mathrm{Cl})$ & $n$ & $\beta(95 \% \mathrm{Cl})$ & $n$ & $\beta(95 \% \mathrm{Cl})$ & $n$ & $\beta(95 \% \mathrm{Cl})$ \\
\hline \multicolumn{11}{|c|}{ Weight-for-length Z-scores } \\
\hline Activity Levelb & 206 & $-0.11(-28,0.05)$ & 157 & $0.07(-0.17,0.30)$ & 153 & $0.14(-0.11,0.39)$ & 132 & $\begin{array}{c}-0.03 \\
(-0.30,0.24)\end{array}$ & 109 & $0.13(-0.13,0.39)$ \\
\hline \multicolumn{11}{|c|}{ Sum of Skinfold Measures } \\
\hline Activity Level & 206 & $\begin{array}{c}-0.93 * \\
(-1.70,-0.16)\end{array}$ & 157 & $\begin{array}{c}-0.43 \\
(-1.67,0.82)\end{array}$ & 153 & $0.09(-1.35,1.53)$ & 132 & $\begin{array}{c}-0.84 \\
(-2.45,0.76)\end{array}$ & 109 & $1.01(-0.09,2.11)$ \\
\hline
\end{tabular}

Adjusted for age at measurement, total calorie intake, breastfeeding status, birthweight, gestational age and sex.

a Beta coefficient and $95 \%$ Confidence Interval

bActivity level subscale from the Infant Behavior Questionnaire-Revised

$* P<0.05$ 
Table 3: Cross-sectional Results: Distress to limitations Temperament Subscale and Infant Anthropometry

\begin{tabular}{|c|c|c|c|c|c|c|}
\hline & \multicolumn{2}{|c|}{3 month visit } & \multicolumn{2}{|r|}{6 month visit } & \multicolumn{2}{|r|}{9 month visit } \\
\hline & $n$ & $\beta(95 \% \mathrm{Cl})^{\mathrm{a}}$ & $n$ & $\beta(95 \% \mathrm{Cl})$ & $n$ & $\beta(95 \% \mathrm{Cl})$ \\
\hline \multicolumn{7}{|c|}{ Weight-for-Length Z-scores } \\
\hline Low DTLb & 48 & $-0.19(-0.53,0.16)$ & 33 & $0.26(-0.25,0.78)$ & 33 & $0.28(-0.22,0.79)$ \\
\hline Mid DTL (referent) & 109 & 0 & 84 & 0 & 82 & 0 \\
\hline High DTL & 49 & $0.15(-0.20,0.49)$ & 39 & $0.01(-0.43,0.45)$ & 38 & $0.24(-0.20,0.67)$ \\
\hline \multicolumn{7}{|c|}{ Sum of 3 Skinfold Measures } \\
\hline Low DTL & 48 & $0.62(-0.99,2.23)$ & 33 & $0.66(-2.15,3.47)$ & 33 & $2.80(-0.08,5.68)$ \\
\hline Mid DTL (referent) & 109 & 0 & 84 & 0 & 82 & 0 \\
\hline High DTL & 49 & $1.32(-0.28,2.92)$ & 39 & $0.12(-2.26,2.50)$ & 38 & $1.78(-0.70,4.25)$ \\
\hline
\end{tabular}

Adjusted for age at measurement, total calorie intake, breastfeeding status, birthweight, gestational age and sex.

a Beta coefficient and $95 \%$ Confidence Interval

bDistress to Limitations (DTL) subscale from the Infant Behavior Questionnaire-Revised

activity level was associated with lower subsequent SF-a one unit increase in maternal perception of infant activity level was associated with a 0.61 unit decrease in SF ( $\beta=-$ $0.61, \mathrm{p}<0.05)$. Similarly, higher activity level was associated with lower subsequent WLZ at nearly all time points with the exception of higher activity level at 9 months of age being associated with higher subsequent WLZ at 12 months (Figure 1).
Distress to limitations was a significant predictor of subsequent fatness and relative weight (Table 5). As compared to infants with moderate DTL, infants with high levels of DTL had higher subsequent SF ( $\beta=1.30, \mathrm{p}=0.01)$ at all subsequent visits. However, high, as compared to moderate levels of DTL were only associated with subsequent higher WLZ at 12 months (Figure 2).

Table 4: Regression results examining overall (fixed) effects of Lagged Activity on Anthropometry

\begin{tabular}{|c|c|}
\hline \multicolumn{2}{|l|}{ OUTCOME = Weight-for-length Z-scores } \\
\hline Variable & $\beta(95 \% \mathrm{Cl})^{\mathrm{b}}$ \\
\hline Lagged Activitya & $-0.16(-0.29,-0.02)^{*}$ \\
\hline Total calories per day & $-0.01(-0.01,0.01)$ \\
\hline Breastfed (yes/no) & $-0.27(-0.70,0.17)$ \\
\hline Breastfed status by total calories interaction term & $0.01(-0.01,0.01)$ \\
\hline 9 month visit & $-0.07(-0.85,0.7 I)$ \\
\hline 12 month visit & $-1.36(-2.24,-0.48)^{*}$ \\
\hline 18 month visit & $-0.71(-1.77,0.34)$ \\
\hline Lagged Activity by 9 month visit interaction term & $0.02(-0.15,0.19)$ \\
\hline Lagged Activity by 12 month visit interaction term & $0.29(0.10,0.48)^{*}$ \\
\hline Lagged Activity by 18 month visit interaction term & $0.14(-0.07,0.35)$ \\
\hline Intercept & $1.32(0.71,1.94)^{*}$ \\
\hline \multicolumn{2}{|l|}{ OUTCOME = Sum of Skinfold Measures } \\
\hline Variable & $\beta(95 \% \mathrm{Cl})^{\mathrm{b}}$ \\
\hline Lagged Activity & $-0.61(-1.19,-0.03)^{*}$ \\
\hline Total calories per day & $-0.01(-0.01,0.01)$ \\
\hline Breastfed (yes/no) & $2.13(-0.53,4.79)$ \\
\hline Breastfed status by total calories interaction term & $-0.01(-0.01,0.01)$ \\
\hline 9 month visit & $-0.51(-1.35,0.33)$ \\
\hline 12 month visit & $-1.21(-2.21,-0.21)^{*}$ \\
\hline 18 month visit & $-1.57(-2.92,-0.22)^{*}$ \\
\hline Intercept & $28.21(25.57,30.86)^{*}$ \\
\hline
\end{tabular}

a Lagged Activity level subscale from the Infant Behavior Questionnaire-Revised

b Beta coefficient and $95 \%$ Confidence Interval

$* \mathrm{P}<0.05$ 


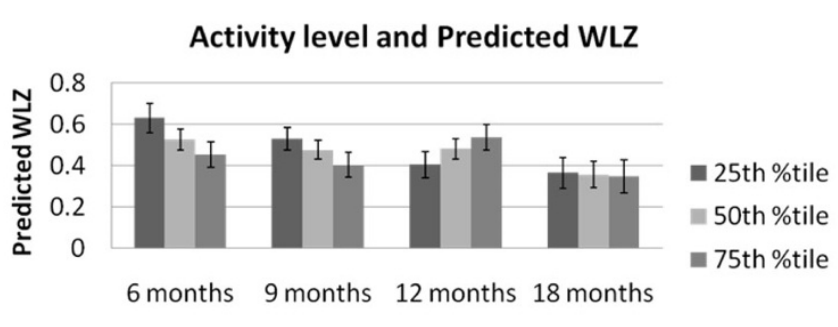

Lagged Activity Level by Visit

\section{Figure I}

Predicted Weight-for-length Z-score by lagged $25^{\text {th }}$, $50^{\text {th }}$, and $75^{\text {th }}$ percentiles of Activity* Level and infant age. * Activity level subscale from the Infant Behavior Questionnaire-Revised.

\section{Discussion \\ Summary of main findings}

Few studies have examined the longitudinal associations between infant temperament and body composition in infancy. This study was conducted to examine the relationship between two temperament subscales and two anthropometric indicators at 3, 6, 9, 12 and 18 months of infant age in a low-income, African American sample at high risk of overweight. Results from cross-sectional and fixed effects longitudinal models differed remarkably. In longitudinal models, increased activity levels were associated with decreased fatness at all time points and with decreased WLZ at nearly all time points, while in crosssectional models activity level was a significant predictor of fatness at only 3 months. High levels of DTL were associated with increased fatness at all time points and increased WLZ at 12 months in the longitudinal models while in cross-sectional models high levels of DTL were not associated with anthropometry at any time point.

\section{Activity Level}

Higher activity level was associated with later decreased fatness. A similar relationship was observed in which higher activity level was associated with later decreased WLZ except at infant age 12 months where the direction of the relationship changed. Similar to our results, Worobey found that leg activity was inversely associated with weight among female infants. [25] In contrast, an early study by Pollitt and colleagues found that heavy Indonesian infants spent more time moving their arms and legs vigorously than did the light infants. [24] Two additional studies showed no association between activity level and subsequent body fatness or weight gain. $[19,26]$

Table 5: Regression results examining overall (fixed) effects of Lagged Distress to Limitations on Anthropometry

\begin{tabular}{l}
\hline OUTCOME = Weight-for-length Z-scores \\
Variable \\
Lagged Low Distress to Limitations ${ }^{\mathrm{a}}$ \\
Lagged High Distress to Limitations $^{\mathrm{a}}$ \\
Total calories per day \\
Breastfed (yes/no) \\
Breastfed status by total calories interaction term \\
9 month visit \\
I 2 month visit \\
Lagged Low Distress to Limitations by 9 month visit interaction term \\
Lagged Low Distress to Limitations by 12 month visit interaction term \\
Lagged High Distress to Limitations by 9 month visit interaction term \\
Lagged High Distress to Limitations by 12 month visit interaction term \\
Intercept
\end{tabular}

\section{$\beta(95 \% \mathrm{Cl})^{\mathrm{b}}$}

$-0.06(-0.34,0.22)$

$-0.04(-0.29,0.21)$

$-0.01(-0.01,-0.01)^{*}$

$-0.31(-0.84,0.21)$

$0.01(-0.01,0.01)$

$-0.04(-0.21,0.12)$

$-0.19(-0.40,0.01)$

$-0.05(-0.43,0.33)$

$0.15(-0.25,0.55)$

$0.01(-0.33,0.34)$

$0.45(0.09,0.80)^{*}$

$0.82(0.56,1.08)^{*}$

\section{OUTCOME = Sum of Skinfold Measures}

Variable

Lagged Low Distress to Limitations

Lagged High Distress to Limitations

Total calories per day

Breastfed (yes/no)

Breastfed status by total calories interaction term Intercept

\section{$\beta(95 \% \mathrm{Cl}) \mathrm{b}$}

$0.67(-0.54,1.89)$

$1.30(0.29,2.31)^{*}$

$0.01(-0.01,0.01)$

$2.40(-0.78,5.59)$

$-0.01(-0.01,0.01)$

$24.86(23.41,26.32)^{*}$

aLagged Distress to Limitations subscale from the Infant Behavior Questionnaire-Revised

bBeta coefficient and $95 \%$ Confidence Interval

$* \mathrm{P}<0.05$ 


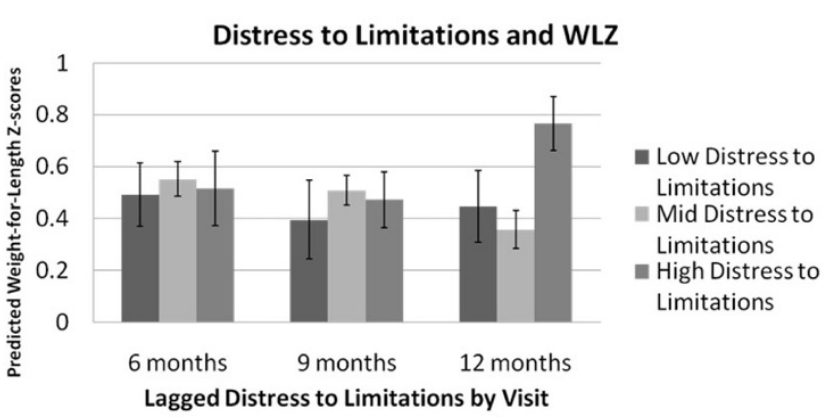

Figure 2

Predicted Weight-for-length Z-score by lagged Distress to Limitations* level and infant age. $*$ Distress to limitations subscale from the Infant Behavior QuestionnaireRevised.

\section{Distress to limitations}

We found an association between high levels of DTL and increased anthropometry, specifically that high DTL was associated with subsequent increased SF values, more in line with hypotheses that would predict increased intake due to efforts to calm fussy infants via feeding. Similarly, high, as compared to moderate levels of DTL were also associated with subsequent increased WLZ, although only at 12 months of infant age. In a cross-sectional study of 50 three-month-old infants Wells et al. found that higher DTL was associated with significantly higher levels of energy expenditure as measured with doubly-labeled water [20], but that DTL was not related to infant fatness. [48] In contrast, other studies before and after Wells et al. have related difficult temperament (which includes fussiness) to increased weight gain in infancy. [19,22,23] One large recent study determined that difficult temperament at 6 months of age was just slightly positively associated with previous rapid weight gain (birth to 6 months) [22] while a much smaller, earlier study showed an association between increased weight for length gain between 6 and 12 months and difficult temperament in the same time period. [19] A third study found that the temperament dimension DTL measured at 8 weeks of infant age was related to previous fast weight gain (birth to 8 weeks). [23] In our sample we did not find any relationship between DTL and change in weight-for-length z-score (results not shown).

\section{Interpretation and Implications}

Two strengths of the current study are the longitudinal nature of the data and the use of lagged temperament variables. Results from cross-sectional and longitudinal models differed considerably. Unobserved mother and infant characteristics may have influenced both temperament and anthropometry. Over time this unobserved heteroge- neity could bias estimates from cross-sectional models. The strength of the fixed effects longitudinal model is that it can eliminate such bias.

Furthermore, the use of lagged temperament variables allows the examination of directionality and temporality in the longitudinal models. One might hypothesize that infant physical growth influences parental perceptions of their infants' temperament. To model the effects of infant temperament on infant anthropometry, we specified our models with lagged infant temperament variables, that is, temperament measured at the visit prior to the measurement of infant anthropometry.

Inconsistencies between our results and earlier studies may be attributed to the longitudinal nature of our data as well as the use of lagged exposure variables which capture directionality. In addition, the same infant behavior, such as high levels of crying and fussiness, may lead to both increased energy expenditure on the part of the infant, and increased intake via additional feedings in attempts to soothe on the part of the parent of that same infant. While we did not find strong evidence that diet mediates the relationship between temperament and WLZ or SF in our sample it has been suggested that persistent, frequent or intense fussy infant behavior which is perceived as difficult may prompt at least some caregivers to use feeding as a strategy to calm distressed infants. [19] Depending on whether the increased intake balances out or exceeds the increased expenditure, different effects on body size and composition at different moments in time in the same infant, and across infants may be observed.

Importantly, our results suggest that infant activity may have differential effects on relative fatness and body size by developmental status. As expected, infants who were perceived by their mothers to have higher activity levels had considerably lower body fat at all subsequent time points. The relationship between activity level and subsequent WLZ scores, however, changed direction at 12 months of infant age. Taken together, these results suggest that infant body composition changes as infant motor development and mobility changes. Infants with higher activity levels are less fat but are more likely gaining muscle weight (as suggested by increased WLZ) when they become more mobile at 12 months of age.

\section{Limitations}

While this dataset offers a unique opportunity to provide information about low-income African American infants, a population at high risk of overweight, the results from this study may not apply to all U.S. infants. Furthermore, comparison of our results with previous studies may be limited by the dissimilarities of the study populations. 
All temperament measures are based on maternal reports: Mothers' perception of infant temperament and behavior may differ by sex, education, or mothers' BMI in other samples, even though we did not find that here.

\section{Conclusion}

In a prospective cohort study of low income AfricanAmerican infants, a group at high risk for the development of obesity, maternal perceptions of infant temperament, or behavioral style significantly contributed to subsequent infant fatness and relative weight, as measured by sum of skin folds and WLZ. In general increased activity levels were associated with later decreased infant skin fold measures and WLZ while increased DTL was associated with later increased infant skin folds. Infant temperament contributes to our understanding of the behavioral contributions to the early development of child fatness and the risk of overweight in the formative months of life. Further research is needed to identify modifiable mediating variables. Identification of such risk factors early in life may help target strategies for establishing healthy lifestyles prior to the onset of overweight.

\section{Abbreviations}

DTL: distress to limitations; WLZ: weight-for-length zscore; SF: skin fold.

\section{Competing interests}

The authors declare that they have no competing interests.

\section{Authors' contributions}

MS conducted all analyses and drafted the manuscript. LA participated in the design of the study and participated in statistical analyses. BDG participated in the design of the study, interpretation of temperament variables and helped to draft the manuscript. JB participated in the design of the study. PB conceived of the study, and participated in its design and coordination and helped to draft the manuscript. All authors read and approved the final manuscript.

\section{Acknowledgements}

The authors thank Dr. Ted Wachs for his helpful comments on an earlier draft of this manuscript. We are grateful to all participating mothers and babies. This research was supported by Grant R0I HD422 19-02 from the National Institutes of Health/NICHD, and by the Mead Johnson Children's Nutrition Small Research Grants Program at the University of North Carolina at Chapel Hill.

\section{References}

I. Ogden CL, Carroll MD, Curtin LR, McDowell MA, Tabak CJ, Flegal KM: Prevalence of overweight and obesity in the United States, 1999-2004. Journal of the American Medical Association 2006, 295: $1549-1555$

2. Mei Z, Scanlon KS, Grummer-Strawn LM, Freedman DS, Yip R, Trowbridge FL: Increasing prevalence of overweight among US low-income preschool children: the Centers for Disease Control and Prevention pediatric nutrition surveillance, I 983 to 1995. Pediatrics 1998, I0I:EI2.
3. Johannsson E, Arngrimsson SA, Thorsdottir I, Sveinsson T: Tracking of overweight from early childhood to adolescence in cohorts born 1988 and 1994: overweight in a high birth weight population. Int J Obes (Lond) 2006, 30:|265- I27|.

4. Deshmukh-Taskar P, Nicklas TA, Morales M, Yang SJ, Zakeri I, Berenson GS: Tracking of overweight status from childhood to young adulthood: the Bogalusa Heart Study. Eur J Clin Nutr 2006, 60:48-57.

5. Rodriguez BL, Fujimoto WY, Mayer-Davis EJ, Imperatore G, Williams DE, Bell RA, Wadwa RP, Palla SL, Liu LL, Kershnar A, et al.: Prevalence of cardiovascular disease risk factors in U.S. children and adolescents with diabetes: the SEARCH for diabetes in youth study. Diabetes Care 2006, 29:189|-I896.

6. Lobstein T, Jackson-Leach R: Estimated burden of paediatric obesity and co-morbidities in Europe. Part 2. Numbers of children with indicators of obesity-related disease. Int J Pediatr Obes 2006, I:33-4I.

7. Raitakari OT, Juonala M, Viikari JS: Obesity in childhood and vascular changes in adulthood: insights into the Cardiovascular Risk in Young Finns Study. Int J Obes (Lond) 2005, 29(Suppl 2):SI0I-104.

8. Baird J, Fisher D, Lucas P, Kleijnen J, Roberts H, Law C: Being big or growing fast: systematic review of size and growth in infancy and later obesity. BMJ 2005, 331:929.

9. Monteiro PO, Victora CG: Rapid growth in infancy and childhood and obesity in later life-a systematic review. Obes Rev 2005, 6: 143-154.

10. Stettler N, Kumanyika SK, Katz SH, Zemel BS, Stallings VA: Rapid weight gain during infancy and obesity in young adulthood in a cohort of African Americans. Am J Clin Nutr 2003, 77: $1374-1378$.

II. Ong KK: Size at birth, postnatal growth and risk of obesity. Horm Res 2006, 65(Suppl 3):65-69.

12. Butte NF, Wong WW, Hopkinson JM, Smith EO, Ellis KJ: Infant feeding mode affects early growth and body composition. Pediatrics 2000, 106:1355-1366.

13. Owen CG, Martin RM, Whincup PH, Smith GD, Cook DG: Effect of infant feeding on the risk of obesity across the life course: a quantitative review of published evidence. Pediatrics 2005, I I5:1367-I377.

14. Kavanagh KF, Cohen RJ, Heinig MJ, Dewey KG: Educational intervention to modify bottle-feeding behaviors among formulafeeding mothers in the WIC program: impact on infant formula intake and weight gain. J Nutr Educ Behav 2008, 40:244-250.

15. Reed BA, Habicht JP, Niameogo C: The effects of maternal education on child nutritional status depend on socio-environmental conditions. Int J Epidemiol 1996, 25:585-592.

16. David V, Moncada M, Ordonez F: Private and public determinants of child nutrition in Nicaragua and Western Honduras. Econ Hum Biol 2004, 2:457-488.

17. Owen GM, Kram KM, Garry PJ, Lowe JE, Lubin AH: A study of nutritional status of preschool children in the United States, 1968-1970. Pediatrics 1974, 53(Suppl):597-646.

18. Sherry B, Mei Z, Scanlon KS, Mokdad AH, Grummer-Strawn LM: Trends in state-specific prevalence of overweight and underweight in 2- through 4-year-old children from low-income families from 1989 through 2000. Arch Pediatr Adolesc Med 2004, I58: I I |6-II 24

19. Carey WB: Temperament and increased weight gain in infants. J Dev Behav Pediatr 1985, 6: I28-I3I.

20. Wells JC, Davies PS: Relationship between behavior and energy expenditure in I2-week old infants. American Journal of Human Biology 1996, 8:465-472.

21. Bates ]: Concepts and measurement of temperament. In Temperament in childhood Edited by: Kohnstamm GA, Bates JE, Rothbart MK. Chichester: Wiley; 1989

22. Niegel S, Ystrom E, Vollrath ME: Is difficult temperament related to overweight and rapid early weight gain in infants? A prospective cohort study. J Dev Behav Pediatr 2007, 28:462-466.

23. Darlington AS, Wright CM: The influence of temperament on weight gain in early infancy. J Dev Behav Pediatr 2006, 27:329-335.

24. Pollitt $E$, Gilmore M, Valcarcel M: Early mother-infant interaction and somatic growth. Early Hum Dev 1978, I:325-336.

25. Worobey J: Temperamental activity and fussiness: implications for weight of 3-mo.-old infants. Percept Mot Skills 200I, 92: $1211-1212$. 
26. Li R, O'Connor L, Buckley D, Specker B: Relation of activity levels to body fat in infants 6 to 12 months of age. J Pediatr 1995, 1 26:353-357.

27. Ogden CL, Kuczmarski RJ, Flegal KM, Mei Z, Guo S, Wei R, Grummer-Strawn LM, Curtin LR, Roche AF, Johnson CL: Centers for Disease Control and Prevention 2000 growth charts for the United States: Improvements to the 1977 National Center for Health Statistics version. Pediatrics 2002, 109:45-60.

28. Rothbart MK, Bates J: Temperament 5th edition. New York: Wiley; 1998.

29. Komsi N, Raikkonen K, Pesonen AK, Heinonen K, Keskivaara P, Jarvenpaa AL, Strandberg TE: Continuity of temperament from infancy to middle childhood. Infant Behav Dev 2006, 29:494-508.

30. Gartstein $M$, Rothbart M: Studying infant temperament via the Revised Infant Behavior Questionnaire. Infant Behavior and Development 2003, 26:64-86.

31. Rothbart MK, Derryberry D, Hershey K: Meaning of parental reports: A contextual approach to the study of termperament and behavior problems in childhood. In Temperament and personality development across the life span Edited by: Victoria J, Molfese DLM. Mahwah, NJ: Erlbaum Associates; 2000.

32. Parade SH, Leerkes EM: The reliability and validity of the Infant Behavior Questionnaire-Revised. Infant Behav Dev 2008, $3 I(4): 637-46$.

33. Putnam SP, Garstein MA, Rothbart MK: Measurement of finegrained aspects of toddler temperament: The Early Childhood Behavior Questionnaire. Infant Behavior and Development 2006, 29:386-40I.

34. Garrett-Peters P, Mills-Koonce WR, Adkins D, Vernon-Feagans L, Cox M: Early environmental correlates of maternal emotion talk. Parenting 2008, 8: II7-I52.

35. Mills-Koonce WR, Propper CB, Gariepy J-L, Blair C, Garrett-Peters $P$, Cox M: Bidirectional genetic and environmental influences on mother and child behavior: The family system as the unit of analyses. Development and Psychopathology 2007, 19:1073-1087.

36. Schuetze P, Eiden RD: The association between prenatal exposure to cigarettes and infant and maternal negative affect. Infant Behavior \& Development 2007, 30:387-398.

37. Hibel LC, Granger DA, Kivlighan KT, Blair C: Individual differences in salivary cortisol: Associations with common over-thecounter and prescription medication status in infants and their mothers. Hormones and Behavior 2006, 50:293-300.

38. Gartstein MA, Knyazev GG, Slobodskaya HR: Cross-cultural differences in the structure of infant temperament: United States of America (U.S.) and Russia. Infant Behav Dev 2005, 28:54-6I.

39. DeVellis R: Scale development: Theory and applications Thousand Oaks, CA: Sage Publications, Inc; 1991.

40. Campbell $D, O E W$ : Sex differences in the activity level of infants. Infant and Child Development 1999, 8:1-17.

41. LampI M, Thompson AL, Frongillo EA: Sex differences in the relationships among weight gain, subcutaneous skinfold tissue and saltatory length growth spurts in infancy. Pediatr Res 2005, 58: $1238-1242$.

42. Harvey NC, Poole JR, Javaid MK, Dennison EM, Robinson S, Inskip HM, Godfrey KM, Cooper C, Sayer AA: Parental determinants of neonatal body composition. I Clin Endocrinol Metab 2007, 92:523-526.

43. Ferreira I, Horst $\mathrm{K}$ van der, Wendel-Vos W, Kremers S, van Lenthe F], Brug J: Environmental correlates of physical activity in youth - a review and update. Obes Rev 2007, 8:129-154.

44. Stata statistical software, release $\mathbf{1 0 . 0}$ for Windows. College Station, TX: StataCorps; 2008.

45. Cleveland WS, Devlin S): Locally Weighted Regression: An Approach to Regression Analysis by Local Fitting. Journal of the American Statistical Association 1988, 83:596-610.

46. Baron RM, Kenny DA: The moderator-mediator variable distinction in social psychological research: conceptual, strategic, and statistical considerations. J Pers Soc Psychol 1986, 5 I:II73-1182

47. Frees EW: Longitudinal and Panel Data: Analysis and Applications in the Social Sciences Cambridge University Press; 2004.

48. Wells JC, Stanley M, Laidlaw AS, Day JM, Stafford M, Davies PS: Investigation of the relationship between infant temperament and later body composition. Int J Obes Relat Metab Disord 1997, 2 1:400-406.
Publish with Biomed Central and every scientist can read your work free of charge

"BioMed Central will be the most significant development for disseminating the results of biomedical research in our lifetime. "

Sir Paul Nurse, Cancer Research UK

Your research papers will be:

- available free of charge to the entire biomedical community

- peer reviewed and published immediately upon acceptance

- cited in PubMed and archived on PubMed Central

- yours - you keep the copyright 